\title{
FROM THE EDITOR: A NOTE OF THANKS
}

Technostyle has undergone some changes in the last while, some happy, some sad. Elenor Winter-Friesen, our invaluable editorial assistant, is pregnant -- happy news indeed after her illness of not so long ago. The baby is due in early March, and all looks well. But that means Elenor will not be in the office for awhile, perhaps permanently!

And that is the sad part. I will miss her quiet efficiency and wonderful good humour. When all would seem impossibly complicated or hopelessly beyond the deadline, Elenor would smile, shrug, and say: "We'll see what we can do." And she would do it! Deadlines would be met, the journal would be published, and copies would be sent to the members, all in good time and all in good order.

Elenor loved working on the journal, and saw it as one of the highlights of her position in the Department of Electrical \& Computer Engineering. That dedication showed in the quality of her work on the journal.

As an organization, we owe her a great deal. As the editor, I can only marvel at her outstanding contribution.

Thanks, Elenor. We wish you well. 